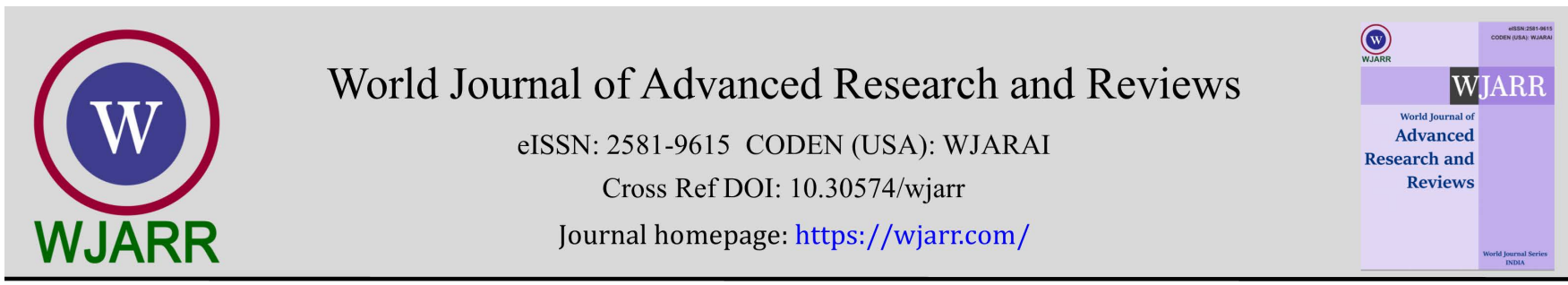

(CASE REPORT)

Check for updates

\title{
COVID 19 vaccine induced glycaemic disturbances in DM2 -A Case Report
}

\author{
A S V Prasad * \\ Former faculty member, Department of Internal Medicine, G. I. T. A. M. Dental College, G. I. T. A. M. University Campus, \\ Rushikinda, Visakhapatnam, Andhra Pradesh, India.
}

World Journal of Advanced Research and Reviews, 2021, 10(03), 149-156

Publication history: Received on 25 May 2021; revised on 06 June 2021; accepted on 09 June 2021

Article DOI: https://doi.org/10.30574/wjarr.2021.10.3.0247

\begin{abstract}
The possibility of disturbances in Blood Sugar (BS) levels of Diabetes Mellitus (DM2) patients, following vaccination for Covid 19, is suggested, but not proved. No documented proof that vaccination actually disturbs the BS, is lacking. This article presents the first documented case of disturbed blood sugar, in a patient with DM2, on insulin, following vaccination for Covid 19 (Covishield).It is observed that initially there is increased Insulin Resistance, (IR) resulting in hyperglycaemia, which is temporary, self-limiting and doesn't call for any increase in insulin dosage.This is followed by a more critical period, when there is increased insulin sensitivity, requiring decrease the pre- vaccination dose of insulin, as the risk of hypoglycemia is observed, as in the case under consideration. Hence, close monitoring and titration of revised insulin dosage, is called for, using a glucometer, during this second phase. Ultimately, the BS and insulin sensitivity/IR, return to the pre-vaccination levels. These disturbances may not come to light, unless the BS, following Covid 19 vaccination, is closely monitored. It is not predictable as to, in whom these disturbances in BS might occurs, and why it does so. The above inferences drawn are based on objective interpretation of the, truthfully recorded observations, during the case study period.
\end{abstract}

Keywords: Covishield; Covaxin; Covid vaccines; Hyperglycaemia; Covid vaccine induced insulin resistance; Insulin sensitivity

\section{Introduction}

It is not intended to review, in this article, the merits and demerits or safety profiles of the various vaccines available for Covid 19, as the same are reviewed extensively, elsewhere [1-6]. The different brands of Vaccines available presently for Covid 19, are updated by, centre for disease control, America, (CDC), on April 2021. Ramesh Pal, Sanjay Kumar Bhadada, and Anoop Misra (March-April2021), extensively reviewed the concepts and challenges of Covid 19 vaccination in diabetics [7]. The Drug Controller General of India announced the approval on 3 rd January 21, basing on the acceptance of the Central Drugs Standard Control Organization (CDSCO), the recommendations of its Subject Expert Committee (SEC), for two Covid-19 vaccines in India, I.e, Covaxin and Covishield for limited, emergency use, and in public interest. Serum Institute of India (SII), has manufactured Covishield, the Indian variant of the AZD1222 vaccine developed by Oxford University and AstraZeneca.The other vaccine that has got emergency use authorization, Covaxin is, manufactured by Hyderabad-based Bharat Biotech in collaboration with the Indian Council of Medical Research (ICMR), New Delhi, India. DM2 is a well-known risk factor for Covid 19. Diabetes is a major risk factor for adverse outcomes in Covid 19 [8]. An important aspect of the SARS-CoV-2 vaccine development is, caring for people with diabetics [9]. The United kingdom (UK) has also prioritized COVID-19 vaccination in patients with DM . The World Health Organization (WHO) Strategic Advisory Group of Experts (SAGE) on Immunization has recommended the use of

\footnotetext{
* Corresponding author: A S V Prasad
}

Department of internal medicine, G.I. T. A M Dental college, G I T A M University Campus, Rushikinda, Visakhapatnam, Andhra Pradesh, India. 
the Oxford-AstraZeneca vaccine (AZD1222) in people with comorbidities that have been identified as increasing the risk of severe COVID-19, including DM2 [10].The vulnerability of diabetics to secondary infections, leading to morbidity and mortality is recognized.SRAS-CoV 2 virus targets the pancreas, resulting in impaired glucose metabolism, and hyperglycaemia [11]. Several vaccine trials included a large number of diabetic volunteers The Pfizer-BioNtech trial included 3, 150 people with diabetes (8.4\% of trial participants). The Moderna trial included 2, 858 people with type 1 , type 2, and gestational diabetes (9.4\% of trial participants).( News \& Blog 2021 January Diabetes and the COVID-19 Vaccine). The data on any disturbances of glycaemic control of diabetic volunteers, if any, is also, not readily available, from the vaccine manufacturer, including the two Covid vaccines produced in India.The fact sheets released by these vaccine companies, as well as several reviews that appeared in the literature on the side effects of the Covid vaccines, are not explicit about this matter (Source: News - International Diabetes Federation 22-Mar2021) . However, there are a couple of suggestions, in the news blogs on Covid vaccine, that the Covid vaccines might disturb the glycaemic status of the diabetic recipients of the vaccine. Even a couple of explanations are offered, as mechanisms for this disturbance in BS, in the Covid19 vaccine news blogs One suggestion is that Covid vaccine induces "an infection like state that might increase insulin requirement or insulin resistance leading to hyperglycaemia. (News \& Blog 2021 January Diabetes and the COVID-19 Vaccine). The other mechanism suggested is that the vaccine induces an immune reaction in the recipient's body which needs extra sugar for energy and hence the resulting hyperglycaemia. No authentic references could be provided for the aforesaid mechanisms but their sources can be traced. This author does not vouch for or against any of those mechanisms nor interested in adding one more. The intention of the article is to present a documented case of disturbed BS after taking Covishield vaccine. In the author's opinion, this is the first documented case report of hyperglycaemia, following Covid vaccination.

\section{Case details}

The patient is a 73 years old male. His comorbidities are, DM 2 for about 3 decades, presently under control, till the time of taking the Covishield vaccine for Covid 19. (Table 2) He is under treatment with a combination of basal, and bolus insulin together amounting to $110 \mathrm{IU}$ (Bolus insulin- 65 and basal insulin of 45 Undistributed between Breakfast, lunch and dinner). He had inferior wall Myocardial Infarction (MI), for which, a stent was placed in the right coronary artery (RCA) in 2004. Had Non- STEMI, in 2017, which is treated by medical management and hypothyroidism in 2020 which is brought under control presently with 75 mcg of eltroxin. He took Covishield on $18^{\text {th }}$ of March 21, uneventfully. As a part of quarterly general check-up is done on $24 / 3$ /21, when the Fasting Blood Sugar (FBS) is reported to be $215 \mathrm{mg} / \mathrm{dl}$ (contrary to regular FBS of around $90 \mathrm{mg} / \mathrm{dl}$ ). The repetition of the test on the same sample yielded the same result. The patient is quite unaware of this disturbance in BS, till the report came. There is no immediate discernible cause for the hyper glycaemia observed after vaccination for Covid19, including infection, injury or recent surgery. His BS and $\mathrm{HbA1C}$ are within control range prior to vaccination (table 2). The BS from the day after the report and a week following the Covid 19 vaccination, ( from 25/3/21) is monitored regularly by glucometer and the readings are recorded. His renal, blood, electrolyte and liver profiles are normal. The patient took the second dose of Covishield vaccine on 28/5/21. There are no additional glycaemic disturbances other than those under follow up since the first dose.

\section{Discussion}

The total duration of observation (study period) of the case is about 10 weeks (from 24/3/21 to 5/6/21). The observations on BS and insulin dosage are recorded in the tables 1 to 6 , the details of which are broached subsequently in this ongoing discussion.

Table 1 FBS and HbA1C lab reports pre and post vaccination

\begin{tabular}{|c|c|c|l|}
\hline Date & FBS & HbA1C & \\
\hline $12 / 9 / 2020$ & $81 \mathrm{mg}$ & 6.6 & Pre vaccination \\
\hline $10 / 12 / 2020$ & $92 \mathrm{mg}$ & 7.1 & Pre vaccination \\
\hline $24 / 3 / 2021$ & $215 \mathrm{mg}$ & 8 & Post vaccination \\
\hline
\end{tabular}

It is inferred from the data recorded in the tables, that initially there is increased insulin resistance /decreased insulin sensitivity, after the COVID-19 vaccination, followed by decreased insulin resistance/ increased insulin sensitivity, as compared with the pre-vaccination levels .The implication of the increased IR in the first phase, is that there is Hyperglycaemia .This is evident from the glucometer readings recorded in the tables 2 and 3). The same prevaccination doses of insulin are continued without upgrading and it is observed that the ra 
ised BS levels, in the first phase slowly returned back to pre-vaccination level (table 2). It is therefore hypothesized, that the initial increased IR is temporary, self-limiting and does not call for revision of the insulin dose ready in use, before the vaccination is given. This first phase lasted for about 25 days ie (from $24 / 3 / 21$ to 18/4/2), since it has come to our notice. This is the period, where greatest restraint is needed to overcome the temptation to increase the insulin dose.

Table 2 Fasting blood sugar (FBS) follow up, post vaccintionally with pre-vaccine doses of the insulin

\begin{tabular}{|c|c|c|}
\hline Date & Reading (FBS) & Comments \\
\hline $24 / 3 / 21$ & $215 \mathrm{mg}$ & Laboratory report \\
\hline $25 / 3 / 21$ & $167 \mathrm{mg}$ & glucometer reading \\
\hline $26 / 3 / 21$ & $147 \mathrm{mg}$ & -----DO----- \\
\hline $27 / 3 / 21$ & $135 \mathrm{mg}$ & ---- DO------ \\
\hline $28 / 3 / 21$ & $121 \mathrm{mg}$ & -----DO----- \\
\hline $29 / 3 / 21$ & $123 \mathrm{mg}$ & ------DO----- \\
\hline $30 / 3 / 21$ & $157 \mathrm{mg}$ & ------DO----- \\
\hline $31 / 3 / 21$ & $135 \mathrm{mg}$ & ------DO----- \\
\hline $1 / 4 / 21$ & $145 \mathrm{mg}$ & ------DO----- \\
\hline $2 / 4 / 21$ & $132 \mathrm{mg}$ & ------DO----- \\
\hline $3 / 4 / 21$ & $121 \mathrm{mg}$ & ------DO----- \\
\hline $4 / 4 / 21$ & $124 \mathrm{mg}$ & ------DO----- \\
\hline $5 / 4 / 21$ & $122 \mathrm{mg}$ & ------DO----- \\
\hline $6 / 4 / 21$ & $126 \mathrm{mg}$ & ------DO----- \\
\hline $7 / 4 / 21$ & $126 \mathrm{mg}$ & ------DO----- \\
\hline $8 / 4 / 21$ & $77 \mathrm{mg}$ & ------DO----- \\
\hline $11 / 4 / 21$ & $84 \mathrm{mg}$ & ------DO----- \\
\hline $12 / 4 / 21$ & $88 \mathrm{mg}$ & ------DO----- \\
\hline $14 / 4 / 21$ & $82 \mathrm{mg}$ & Glucometer \\
\hline
\end{tabular}

The second phase of increased insulin sensitivity, began with a brief and apparent return to pre-vaccination levels of BS, for a week which lasted for 7 days $(8 / 4 / 21-14 / 4 / 21)$ but at a total insulin dose less than the pre-vaccination dose and the effect is temporary. Hence it is called apparent return to normal B S levels. It is then heralded by the sudden onset of hypoglycaemia, the pre-lunch BS dropping to $50 \mathrm{mg} / \mathrm{dl}$, on $19 / 4 / 21$, with the Pre-vaccination dose of Insulin that did not cause any problem in the first phase. This second phase is characterised by increased insulin sensitivity /decreased IR, just the opposite of what is seen in the first phase. The implication of this phase is that the same prevaccination insulin doses demonstrated increased neutralizing power of the insulin, as indicated by what the author likes to call as the increased ' insulin neutralization factor' (INF) as shown in table 3. This parameter is used by the author to compare the insulin sensitivity at various doses of insulin, and on different days and is not a parameter described before, in the literature, but instead, coined for the author's use. The INF is calculated by dividing the total BS in mgs / $\mathrm{dl}$ at breakfast (BF), lunch and dinner, taken together, with the total dose of insulin administered, during aforesaid periods. The values help monitor the changes in insulin sensitivity as well as calculating the required insulin dose. While tables 3 helps to understand the day to day changes in insulin sensitivity, table 4 helps to understand the same changes in the BS / insulin sensitivity that occurred between breakfast (BF) and lunch (post BF/pre -lunch period) respectively. The increased insulin sensitivity could be better appreciated when compared to the pre-vaccination base levels. The pre vaccination total blood sugar load /day is about $320 \mathrm{mg}$ (BF $80 \mathrm{mg}$, lunch and dinner, $120 \mathrm{mg}$ each) and the total insulin dose in use then which is, $110 \mathrm{IU}$, the ratio of both works out to be approximately to 3 which is the prevaccination INF. Incidentally, this is the end point aimed to be achieved, when the post vaccine BS and insulin doses are stabilized. The implications of this phase of increased insulin sensitivity is, that the continuation of insulin at the same pre-vaccination doses if not titrated as per BS levels, may cause hypo glycaemia. This is a real rather than theoretical risk, as evidenced by the near hypoglycemia levels to which the BS dropped on four occasions. I.e., on 19/5/21 (BS 50 $\mathrm{mg} / \mathrm{dl}$ ), on $25 / 4 / 21$ (BS $59 \mathrm{mg} / \mathrm{dl}$ ), and lastly on 03/5/21(BS $67 \mathrm{mg} / \mathrm{dl}$ ) as could be verified from the table 3 . The $4^{\text {th }}$ 
instance of near hypoglycemia (65 mg/dl) occurred on 23/5/21 at pre-lunch period on a revised BF dose of inj. Actrapid, $15 \mathrm{IU}$ and inj insulated $18 \mathrm{IU}$. So unlike the first phase, no fixed dose of insulin could be given on every day, as the insulin response varied, not only from day to day but also within the same day, between $\mathrm{BF}$, lunc Insulatard $\mathrm{h}$ and dinner, as could be seen from the tables 3. So, this period calls for close and frequent monitoring of the BS before every dose of insulin given. Another problem is the insulin response is erratic as evident from the table 4, which shows that the response of a fixed insulin dose (15 IU of inj Actrapid and 15 IU of inj, is unpr edictable from day to day, making it difficult to arrive at a fixed insulin regimen that could be followed on day to day basis without resorting to BS testing, every time. Similar is such erratic insulin response with other doses repeated for few days as could be seen from table3. Such unpredictable insulin response is also seen between lunch and dinner and dinner and next day B F. The time taken to stabilize to the pre-vaccination doses of insulin, could be arduous and time consuming, as exemplified by the present cases. The rate of decrease in insulin sensitivity to the pre-vaccination, ISF is the only guide to the duration that might be required for the return to pre-vaccination status. The total insulin requirement before and after the vaccination, as well as its breakup details are furnished in table 5.

Table 3 BS readings and insulin doses, fasting, Pre-lunch and pre-dinner

\begin{tabular}{|c|c|c|c|c|c|}
\hline Date & $\begin{array}{l}\text { FBS / insulin } \\
\mathrm{mg} / \mathrm{dl}\end{array}$ & $\begin{array}{l}\text { Pre-lunch } \\
\text { BS/insulin }\end{array}$ & $\begin{array}{l}\text { Predinner } \\
\text { BS/insulin }\end{array}$ & $\begin{array}{l}\text { Total } \\
\text { insulin/day }\end{array}$ & $\begin{array}{l}\text { BS: } \\
\text { insulin } \\
\text { Ratio }\end{array}$ \\
\hline $19 / 4 / 21$ & 95 (A.15, I .20) & 50 (No insulin) & 75 (no insulin) & - & - \\
\hline $21 / 4 / 21$ & 107 (A10, i 10) & 94 (A 10) & 91 (A 10, I 10) & $50 \mathrm{IU}$ & 5.84 \\
\hline $22 / 4 / 21$ & $98(\mathrm{~A} 10, \mathrm{i} 10)$ & 128 (A 10) & $96(\mathrm{~A} 10, \mathrm{i} 10)$ & $50 \mathrm{IU}$ & 6.44 \\
\hline $23 / 4 / 21$ & $154(\mathrm{~A} 15, \mathrm{i} 10)$ & 124. (A 10) & 127 (A10, i 10) & $55 \mathrm{IU}$. & 7.36 \\
\hline $24 / 4 / 21$ & $164(\mathrm{~A} 15, \mathrm{i} 10)$ & 76 (A 10) & $.111(\mathrm{~A} 15, \mathrm{i} 10)$ & $60 \mathrm{IU}$. & 5.85 \\
\hline $25 / 4 / 21$ & $121(\mathrm{~A} 15, \mathrm{i} 10)$ & $59($ no $A)$ & 121 (A15, I 15) & $55 \mathrm{IU}$ & 5.47 \\
\hline $26 / 4 / 21$ & $131(\mathrm{~A} 15, \mathrm{i} 15)$ & 121 (A 12) & 118 (A18, i 12) & $72 \mathrm{IU}$. & 5.14 \\
\hline $27 / 4 / 21$ & 133 (A15, I 10) & 78 (A 10) & 101 (A18, i 12) & $65 \mathrm{IU}$ & 4.80 \\
\hline $28 / 4 / 21$ & $96(A 15$, i 10) & $132(\mathrm{~A} 10)$ & 106 (A18, I 12) & $65 \mathrm{IU}$ & .5 .14 \\
\hline $29 / 4 / 21$ & $129(\mathrm{~A} 15, \mathrm{i} 10)$ & 106 (A 10) & $96(\mathrm{~A} 18, \mathrm{i} 12)$ & $65 \mathrm{IU}$ & 5.09 \\
\hline $30 / 4 / 21$ & $128(\mathrm{~A} 15, \mathrm{i} 15)$ & 111(A 10) & 133 (A 18, i 18) & $76 \mathrm{IU}$ & 4.89 \\
\hline $1 / 5 / 22$ & 120 (A 15, i 15) & 74 (A 10) & 107 (A20, i20) & $80 \mathrm{IU}$ & 3.76 \\
\hline $2 / 5 / 21$ & 106 (A15, i 15) & 107 (A 10) & 125 (A23, i 23) & $86 \mathrm{IU}$. & 3.93 \\
\hline $3 / 5521$ & 67 (A12, i 12) & 90 (A 10) & $94(\mathrm{~A} 20, \mathrm{i} 20)$ & $74 \mathrm{IU}$. & 3.34 \\
\hline $4 / 5 / 21$ & 115 (A15 i15) & 55 (A NIL) & 172 (A 20, i20) & $70 \mathrm{IU}$. & 4.88 \\
\hline $5 / 5 / 21$ & 146 (A 15, i 15) & 110 (A 10) & 112 (A18, i 18) & $76 \mathrm{IU}$. & 4.84 \\
\hline $6 / 5 / 21$ & 113 (A 12, i12) & $\mathrm{NT}^{*}$ & $95(\mathrm{~A} 18, \mathrm{i} 18)$ & $* *$ & $* * *$ \\
\hline $7 / 5 / 21$ & 101 (A 12, I 12) & $\mathrm{NT}^{*}$ & 105 (A18 i 18) & $* *$ & $* * *$ \\
\hline $8 / 5 / 21$ & 136 (A 12, i 12) & $\mathrm{NT}^{*}$ & $112(\mathrm{~A} 20, \mathrm{i} 20)$ & $* *$ & $* * *$ \\
\hline $9 / 5 / 21$ & 114 (A 12, i 12) & $\mathrm{NT}^{*}$ & $122(\mathrm{~A} 22, \mathrm{i} 22)$ & $* *$ & $* * *$ \\
\hline $10 / 5 / 21$ & 98 (A 12, I 12) & $\mathrm{NT}^{*}$ & 134 (A 22, i 22) & $* *$ & $* * *$ \\
\hline $11 / 5 / 21$ & 128 (A15, i.15) & 90. (A 12) & 103 (AA.22, I22.) & $86 \mathrm{IU}$ & 3.73 \\
\hline $12 / 5 / 21$ & 123 (A15, i.15) & 127 (A 15) & 95 (A22, I 22) & 89 IU. & 3.87 \\
\hline $13 / 5 / 21$ & 105 (A15, i15) & 76 (A 15) & 76. (A 22, I 22) & 89 IU. & 2.88 \\
\hline
\end{tabular}




\begin{tabular}{|c|c|c|c|c|c|}
\hline $14 / 5 / 21$ & 98 (AA15, I 15) & 84 (A 15) & 106. (A 24, I 24) & $93 \mathrm{IU}$ & 3.10 \\
\hline $15 / 5 / 21$ & 124 (A 15., i15) & 91 (A 18) & 131. A 25, I 25) & $98 \mathrm{IU}$ & 3.53 \\
\hline $16 / 5 / 21$ & $98(\mathrm{~A} 15, \mathrm{i} 15)$ & 59/178 (A 10) & 100 (A.24 I. 24) & $88 I U$ & 4.27 \\
\hline $17 / 5 / 21$ & 114 (A 14, I 14) & $110(\mathrm{~A} 16)$ & $136($ A..25, i 25) & $94 \mathrm{IU}$ & 3.82 \\
\hline $18 / 5 / 21$ & $101(\mathrm{~A} 14, \mathrm{i} 14)$ & 113 (A.18) & 95. (A 25I. 25) & $96 \mathrm{IU}$ & 3.21 \\
\hline $19 / 5 / 21$ & $114(\mathrm{~A} 14, \mathrm{i} 14)$ & 113 (A.18) & 89 (A 24 I 24) & $94 \mathrm{IU}$ & 3.36 \\
\hline $20 / 5 / 21$ & $101(\mathrm{~A} 15, \mathrm{i} 15)$ & 101 (A 18) & 99 (A 25, i 25) & $98 \mathrm{IU}$ & 3.07 \\
\hline $21 / 5 / 21$ & $80(\mathrm{~A} 15, \mathrm{i} 15)$ & $104(\mathrm{~A} 20)$ & 96 (A25, I 25) & $100 \mathrm{IU}$ & 2.8 \\
\hline $23 / 5 / 21$ & 98 (A 15, i 18) & 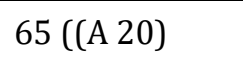 & 116 (A 25, i 25) & $103 \mathrm{IU}$ & 2.79 \\
\hline $24 / 5 / 21$ & 82 & & & & \\
\hline
\end{tabular}

\section{Inferences}

- $\quad$ Range of insulin sensitivity $2.8-7.36$

- Average increase in insulin neutralizing capacity. 4.4

- Insulin sensitivity in Ascending order: 2.8, 2.88, 3.0, 3.1, 3.21, 3.34, 3.36, 3.53, 3.73, 3.76, 3.82, 3.87, 4.27 80, $4.84,4.88,4.89,5.09,5.145 .14,5.47,5.84,5.85,6.44,7.36$

- As on date, the total dose of insulin given is $103 \mathrm{IU}$, as against the Prevaccination dose of 110 IU. Hence fluctuations in FBS might occur for a couple of days before the pre-vaccination insulin dose of $110 \mathrm{IU} /$ day is achieved. (See table 6)

- The goal of management is to achieve an insulin dose/day, which obviates the necessity of frequent and repeated BS testing. Going by the decreasing trends of insulin sensitivity, the target level of glycaemia as well as, the target dose of total insulin would not be far off.

Table 4 The effect of B F dose of A15, I 15 insulin on pre-lunch BS levels

\begin{tabular}{|c|c|c|c|c|}
\hline Date & Fasting & pre-Lunch & Difference & $\begin{array}{l}\text { BS: insulin } \\
\text { Ratio (INF) }\end{array}$ \\
\hline $26 / 4 / 21$ & $131(\mathrm{~A} 15, \mathrm{i} 15)$ & 121 (A 10) & $(-) 10$ & 6.30 \\
\hline $30 / 4 / 21$ & $128(\mathrm{~A} 15, \mathrm{I} 15)$ & 111 (A 10) & $(-) 17$ & 5.98 \\
\hline $1 / 5 / 22$ & $120(\mathrm{~A} 15, \mathrm{i} 15)$ & 74 (A 10) & $(-) 46$ & 4.85 \\
\hline $2 / 5 / 21$ & $106(\mathrm{~A} 15, \mathrm{i} 15)$ & 107 (A 10) & (+) 01 & 5.32 \\
\hline $4 / 5 / 21$ & 115 (A15 i15) & 55 (A 10) & $(-) 60$ & 4.25 \\
\hline $5 / 5 / 21$ & 146 (A 15, i 15) & 110 (A 10) & $(-) 36$ & 6.40 \\
\hline $11 / 5 / 21$ & $128(\mathrm{~A} 15, \mathrm{i} .15)$ & 90 (A 10) & $(-) 38$ & 5.45 \\
\hline $13 / 5 / 21$ & $105(\mathrm{~A} 15, \mathrm{i} 15)$ & 106 (A 10) & $(+) 1$ & 5.27 \\
\hline $14 / 5 / 21$ & 98 (AA15, i15) & 91 (A 10) & $(-) 07$ & 4.72 \\
\hline $15 / 5 / 21$ & 124 (A 15, i15) & 59 (A 10) & $(-) 65$ & 4.57 \\
\hline $16 / 5 / 21$ & $98(\mathrm{~A} 15, \mathrm{i} 15)$ & 110 (A 10) & $(+) 12$ & 5.20 \\
\hline
\end{tabular}




\section{Inferences}

- At the same dose of insulin, day to day fluctuations in the insulin sensitivity is observed.

- Average reduction in BS $(293 \div 11)=6.63$

- $\quad$ Range of insulin sensitivity 4.25 to 6.4

- $\quad$ Average insulin sensitivity - $(58.31 \div 11)=5.30$

Table 5 Total Insulin requirement before and after vaccination with breakup

\begin{tabular}{|c|c|}
\hline $\begin{array}{l}\text { Before Vaccination } \\
\text { Total dose of insulin }\end{array}$ & $\begin{array}{l}\text { After vaccination } \\
\text { Total dose of insulin }\end{array}$ \\
\hline \multirow[t]{2}{*}{$110 \mathrm{IU}$} & $103 \mathrm{IU}$ (as on $23 / 5 / 21$ ) \\
\hline & $\begin{array}{l}110 \mathrm{IU} \text { (between } 31 / 5 / 21 \\
\text { to } 5 / 6 / 21 \text { ) }\end{array}$ \\
\hline \multicolumn{2}{|l|}{ Break fast } \\
\hline A. 15 IU & $15 \mathrm{IU}$ \\
\hline I. $20 \mathrm{IU}$ & $20 \mathrm{IU}$ \\
\hline \multicolumn{2}{|l|}{ Lunch } \\
\hline A.25 IU & $25 \mathrm{IU}$ \\
\hline \multicolumn{2}{|l|}{ Dinner } \\
\hline A. $25 \mathrm{IU}$ & $25 \mathrm{IU}$ \\
\hline I. 25 IU & $25 \mathrm{IU}$ \\
\hline
\end{tabular}

Even in the present case the decreasing ISF is discernible and it may take some more time to return to pre-vaccination insulin dose and ISF. This second stage lasted for about 6 weeks (21/4/21 - $30 / 5 / 21)$ This followed by a stage of final recovery of BS levels, with pre- vaccination doses of insulin. (table 6) This stage is observed for about a week. (31/5/ 21 to $5 / 6 / 21)$.

\subsection{Two interesting observations made during the post-vaccination period}

- Till the pre-vaccination dose of insulin is achieved, the disturbance in the BS is limited to FBS only, as could be observed from the relevant tables. The implication is that hepatic glucose output (gluconeogenesis) is affected. The Liver function tests, (LFT) done as a part of routine general checkup on 24/3/21, are within normal limits. Understandably, the disturbance appears to be at molecular level.

- During the past 3 years are so, the patient is on Oglibose $0.3 \mathrm{mg}$, (a glucosidase inhibitor) before lunch and metformin $850 \mathrm{mg}$ SR (an insulin sensitizer) before dinner, as a top- up measure to control PLBS and FBS, at that time. Since then, the patient is using continuously, the above two tablets. Presently, the BS levels are under control, with pre-vaccination doses of both bolus and basal insulin, without using either of them, since the last week of the study period. They are reserved in case the PLBS or FBS are disturbed in the near future.

\subsection{The cause and effect}

The hypothesis, that the disturbance in BS levels is related to the Covid 19 vaccine, is supported by the following arguments.

- The disturbance in the BS, followed soon after the first dose of vaccination for Covid 19 (Covishield) and there is no particular cause like presence of an infection, injury or recent surgery, that could have raised the insulin demand resulting in hyperglycemia, initially. Even if it is considered to be due to any of the above causes, it should have required more insulin, which is not the case here. Increased insulin resistance or decreased insulin sensitivity, both or either of these could be operating, behind the hyperglycaemia, in the first phase. 
- The previous 6 month's reports of FBS and HbA1c are within acceptable levels of diabetic control. The recent HbA1C report shows a marginal raise in HbA1C over the past 6 months, which suggests that the cause for the disturbance in $\mathrm{BS}$, is recent. The recent event that happened is the Covid 19 vaccination.

- That the BS levels, should return to pre-vaccination levels on its own and without any change in the insulin schedule or diet. This is so, as evidenced by the BS readings of the table 1, during the first phase of hyperglycemia.

- The absence of any specific cause for the BS disturbance except for the vaccination for Covid 19 which is suggested to cause hyperglycaemia as per the literature reviewed in the introduction part of this article.

- Further to it, the 4 episodes of near hypoglycemia, that occured with doses well within the pre-vaccination dose of insulin, is proof enough, of the increased sensitivity of insulin in the second phase. This fact is corroborated by the figures in the tables 3 and 4, as indicated by the BS: total insulin ratios.

- There is no known cause that could be ascribed to the increased insulin sensitivity in the second phase. This, in the absence of any other accountable cause, puts the onus on the Covid vaccine. Since all the above facts point towards the vaccination given for Covid 19, as the cause for the glycaemic disturbances observed in the case cited., the cause and effect thus stand proved. To be more explicit, the cause is the covishield vaccination and the effect is the biphasic response of the insulin sensitivity/IR, as observed during the period following Covid 19 vaccination.

- The return to pre-vaccine levels of glycaemic control, once the pre-vaccination dose of insulin is achieved gradually (table 6), shows that the effects follow a pattern not explainable by any known cause. The possible role of the vaccination for Covid 19, comes to fore under such circumstances.

- The well documented biphasic response of insulin sensitivity as established, puts beyond any doubt that the cause cannot be anything other than due to the vaccine effect. This is so, as evidenced by the BS readings of the table 1, during the first phase of hyperglycemia, to vaccination for Covid19, in the circumstances in which it is unveiled.

Table 6 FBS on pre- vaccination insulin dosage (in IU)

\begin{tabular}{|l|c|}
\hline Date & $\begin{array}{c}\text { FBS (Daily insulin dose: T 110; BF A15, i } 20 \text {; Lunch } \\
\text { A25; Dinner A 25, I 25) }\end{array}$ \\
\hline $31 / 5 / 21$ & $71 \mathrm{mg} / \mathrm{dl}$ \\
$1 / 6 / 21$ & $77 \mathrm{mg} / \mathrm{dl}$ \\
$2 / 6 / 21$ & $82 \mathrm{mg} / \mathrm{dl}$ \\
$3 / 6 / 21$ & $89 \mathrm{mg} / \mathrm{dl}$ * \\
$4 / 6 / 21$ & $93 \mathrm{mg} / \mathrm{dl} *$ \\
$5 / 6 / 21$ & $95 \mathrm{mg} / \mathrm{dl}$ ** \\
*One medium size mango (seasonal fruit) at Lunch, the day before (to compensate for the low FBS. \\
** one mango at lunch and four pieces of mango $(2 \times 2$ inches) at dinner, the day before) \\
A-Inj Actrapid; I - Insulatard ; T-total )
\end{tabular}

\section{Conclusion}

The author reports for the first time, (subject to verification) a case of DM2 on insulin, where the previously, BS which is under control, is disturbed, following Covid 19 vaccination, with Covishield. The cause and effect are being proved, as seen above. The author's personal opinion is, that the disturbance might be more in those diabetics, who are already on insulin treatment (decompensated DM 2, with no endogenous insulin reserves), than those on oral hypoglycaemic agents (with some existing endogenous insulin and hence compensated DM2). This could be one of the reasons why this phenomenon is not widely appreciated, as diabetics on, oral hypoglycaemic agents (OHA) in general, outnumber those on insulin. This is Important, when any further study is undertaken, as it behoves that such study should include 3 groups, i.e., those, who are on insulin, those on oral hypoglycaemic agents (OHA), along with the normal controls. It is debatable, as to how many diabetics on insulin, develop this observed phenomenon. Here the author would like to draw an analogy. Anaphylaxis might occur in one in one lac, but the absence of such reaction in rest of ninety-nine thousand, nine hundred and ninety-nine, does not negate the possibility of its occurrence. 


\section{Compliance with ethical standards}

\section{Acknowledgments}

My sincere thanks to KNS Vivek, my grandson and medico, for his help in drawing the tables.

\section{Statement of informed consent}

Informed consent of the patient is obtained.

\section{References}

[1] Ella R, Vadrevu KM, Jogdand H, Prasad S, Reddy S, Sarangi V. Safety and immunogenicity of an inactivated SARSCoV-2 vaccine, BBV152: a double-blind, randomised, phase 1 trial. Lancet Infect Dis. 2021 S1473309920309427.

[2] Voysey M, Clemens SAC, Madhi SA, Weckx LY, Folegatti PM, Aley PK. Safety and efficacy of the ChAdOx1 nCoV-19 vaccine (AZD1222) against SARS-CoV-2: an interim analysis of four randomised controlled trials in Brazil, South Africa, and the UK. Lancet. 2021; 397: 99-111.

[3] Novavax COVID-19 vaccine demonstrates 89.3\% efficacy in UK phase 3 trial [Internet]. [cited 2021 Aug 2].

[4] Johnson \& johnson announces single-shot janssen COVID-19 vaccine candidate met primary endpoints in interim analysis of its phase 3 ENSEMBLE trial.

[5] Baden LR, El Sahly HM, Essink B, Kotloff K, Frey S, Novak R. Efficacy and safety of the mRNA-1273 SARS-CoV-2 vaccine. N Engl J Med. 2021; 384: 403-416.

[6] Polack FP, Thomas SJ, Kitchin N, Absalon J, Gurtman A, Lockhart S. Safety and efficacy of the BNT162b2 mRNA covid-19 vaccine. N Engl J Med. 2020; 383: 2603-2615.

[7] Ramesh Pal, Sanjay Kumar Bhadada, Anoop Misra. COVID-19 vaccination in patients with diabetes mellitus: Current concepts, uncertainties and challenges: Diabetes MetabSyndr. 2021 March-April; 15(2): 505-508.

[8] Goeijenbier M, vanSloten TT, Slobbe L, Mathieu C, vanGenderen P, Beyer Walter EP. Osterhaus Albert D.M.E. Benefits of flu vaccination for persons with diabetes mellitus: A review. Vaccine. 2017; 35(38): 5095- 5101.

[9] Bloomgarden Zachary T. Diabetes and COVID-19. Journal of Diabetes. 2020; 12(4): 347- 348.

[10] Interim recommendations for use of the AZD1222 (ChAdOx1-S [recombinant]) vaccine against CoVID- 19 developed by Oxford University and AstraZeneca [Internet]. [cited 2021 Nov 2].

[11] Yang Jin-Kui, Lin Shan-Shan, Ji Xiu-Juan, Guo Li-Min. Binding of SARS coronavirus to its receptor damages islets and causes acute diabetes. ActaDiabetologica. 2010; 47(3): 193- 199. 